\title{
Inter-population segregation in the wintering areas of macaroni penguins
}

\author{
Jean-Baptiste Thiebot ${ }^{1, *}$, Yves Cherel ${ }^{1}$, Phil N. Trathan ${ }^{2}$, Charles-André Bost ${ }^{1}$ \\ ${ }^{1}$ Centre d'Etudes Biologiques de Chizé, UPR 1934 du CNRS, 79360 Villiers-en-bois, France \\ ${ }^{2}$ British Antarctic Survey, Natural Environment Research Council, High Cross, Madingley Road, Cambridge CB3 0ET, UK
}

\begin{abstract}
How top avian predators are distributed at sea during the inter-breeding period remains poorly known. Here we focused on the pelagic seabird that is the single greatest avian consumer of marine resources: the macaroni penguin. Our aims were (1) to investigate where these penguins are distributed whilst at sea during winter, and (2) to determine how their distribution and trophic ecology varies in 1 colony between successive years and between 2 colonies from neighbouring localities at the same time. We surveyed a total of 30 penguins from Crozet and Kerguelen Islands (southern Indian Ocean). Penguins from Kerguelen were tracked in 2006 and 2007, and those from Crozet in 2007. Habitat use was investigated using miniaturised light-based geolocators, and trophic ecology by the use of stable isotope analyses. Results showed large-scale patterns of distribution over deep oceanic waters of the Polar Frontal Zone characterised by a temperature of 3.0 to $3.5^{\circ} \mathrm{C}$ during July. Birds from Kerguelen had a consistent inter-annual winter distribution at the population level. Birds tracked from Crozet were distributed in distinct areas, separate from the birds from Kerguelen. Trophic ecology (blood $\delta^{15} \mathrm{~N}$ value) was very similar between years and colonies, and indicated that these penguins preyed upon low trophic level prey, most probably swarming crustaceans, at the end of winter. We conclude that inter-annual fidelity in winter habitat provides evidence of highly favourable and predictable foraging areas, while the distinct inter-colony distributions suggest very heterogeneous distribution of profitable feeding areas for this species in the southern Indian Ocean.
\end{abstract}

KEY WORDS: Non-breeding period - Philopatry · Segregation · Eudyptes chrysolophus . Habitat use · Stable isotopes · Secondary production

\section{INTRODUCTION}

For over 2 centuries, marine predators and their planktonic prey have been a major focus in attempting to describe and understand pelagic ecosystems (Hardy 1936, Murphy 1936). These 2 trophic groups provide complementary approaches into marine systems, with different insights deriving from different ends of the pelagic food web. For example, even before the existence of satellite-derived data, marine predators were used as cues or bio-indicators to evaluate the biological productivity of certain pelagic areas, with implications for both oceanography and fishing (Pocklington 1979, Furness \& Camphuysen 1997). Today, surface indicators gained from satellite remote sensing are generally recognised as extremely valuable to such studies of oceanography and fishing (e.g. Behrenfeld \& Falkowski 1997, Grémillet et al. 2008). However, all such proxies suffer from a number of drawbacks under certain conditions (see Timmermans et al. 2008 and references therein), and many of these adverse conditions are particularly concentrated in the winter period. Therefore, using pelagic predators may be a unique opportunity to reveal high-seas productive foraging areas that are available during winter (Bost et al. 2004).

The activity schedules of most land-based marine predators are unconstrained by the nutritional status of either their mate or their offspring during winter (Phillips et al. 2005). During this period, these animals 
no longer behave like central-place foragers, and their winter movements may therefore better reflect the large-scale spatial distribution of predictable foraging areas according to the theory of ideal-free distribution (Fretwell \& Lucas 1969). The use of electronic devices deployed on marine animals to track their at-sea movements has considerably increased our knowledge of pelagic ecosystems (see review by Ropert-Coudert \& Wilson 2005). More recently, even the more challenging winter inter-breeding period is becoming better understood, thanks to device miniaturisation and technological advances (Grémillet et al. 2000, Bost et al. 2009, Ballard et al. 2010, Egevang et al. 2010).

In the present study we focused on the single largest marine consumer among seabirds: the macaroni penguin Eudyptes chrysolophus (Brooke 2004). We evaluated whether the winter foraging areas available to these predators when free from breeding constraints were (1) predictable between successive years, and (2) distributed homogeneously. Penguins are difficult to reliably monitor through direct observation during atsea surveys due to their short surface time and low profile above the sea surface, which make them cryptic organisms when foraging. Understanding their at-sea distribution and investigations of their feeding habits over long temporal scales (months) has therefore required technological advances and miniaturisation.

To address our principal hypotheses, we used movement data collected using miniaturised electronic geolocation devices, together with ecotrophic interaction data using stable isotope analyses. The combination of the 2 methods was tested on macaroni penguins from the Kerguelen Islands in winter 2006 and proved to be successful (Bost et al. 2009). This allowed us to compare the at-sea distribution, habitat use and trophic ecology of wintering birds from the same locality between 2 successive years, and between 2 neighbouring localities during the same year. Seabirds from the same colony generally exhibit a highly coherent atsea distribution within years and foraging site philopatry between years (Phillips et al. 2005, Trathan et al. 2006), often resulting in better food localisation and exploitation (Ward \& Zahavi 1973, Clark \& Mangel 1984), perhaps due to cultural effects (e.g. Grémillet et al. 2004). Conversely, conspecifics from different colonies often show divergent patterns (Grémillet et al. 2004, Trathan et al. 2006). Our first prediction was that a constant ecological niche is targeted by these animals. We therefore investigated their foraging habitat using available environmental variables and information about the trophic ecology of these populations during winter. Our second prediction was that parapatric birds may exhibit a mutually exclusive spatial distribution in order to mitigate high levels of potential intraspecific competition. Therefore, tempo- ral and spatial variation in the distribution of penguins should reveal site philopatry between successive years.

\section{MATERIALS AND METHODS}

Study sites and species. Macaroni penguin colonies were studied at Kerguelen and Crozet, 2 archipelagos situated $1400 \mathrm{~km}$ apart in the southern Indian Ocean. Together with the neighbouring Heard Island, these islands are the main breeding localities known for this species in the southern Indian Ocean (ca. 1 to 1.8 million pairs each, BirdLife International 2010). This region is strongly influenced by the Antarctic Circumpolar Current, flowing eastward and including a latitudinal succession of oceanographic fronts (e.g. Belkin \& Gordon 1996, Park et al. 2009). In this study, we focused on 4 of them (from north to south): the Subtropical Front (delimited here by its southern limit, SSTF), the Subantarctic Front (SAF), the Polar Front (PF) and the southern boundary of the Antarctic Circumpolar Current (SACC). These boundaries delimit 4 main water masses in the studied area (from north to south): the Subtropical Zone (STZ, north of the SSTF), the Subantarctic Zone (SAZ, between the SSTF and $\mathrm{SAF}$ ), the Polar Frontal Zone (PFZ, between the SAF and $\mathrm{PF}$ ) and the Antarctic Zone (AZ, between the PF and SACC). It is noteworthy that the location of these oceanographic fronts varies seasonally and their surface definition is not always absolute; moreover, the SAZ is actually poorly defined in the Crozet region, where other oceanic influences such as the Agulhas Current retroflexion take place (Belkin \& Gordon 1996, Park et al. 2009).

The macaroni is a relatively small and sexually dimorphic penguin (Warham 1975). The species is very numerous on a global scale (Woehler 1993) consuming about 9.2 million $t$ of marine resources each year, i.e. more than $13 \%$ of the total amount of food taken by the world's seabirds (Brooke 2004). It feeds mainly on crustaceans and myctophid fish (Croxall \& Prince 1980, Ridoux 1994, Cherel et al. 2007, Deagle et al. 2008). Macaroni penguins breed on subantarctic islands, in small to huge colonies, such as those found at South Georgia and at the Crozet and Kerguelen archipelagos. They spend their entire inter-breeding season (5 to 7 mo) exclusively at sea (Warham 1975). The habitat that they exploit during this period is poorly documented, with only occasional at-sea sightings of birds, usually with unknown status and origin (J. C. Stahl et al. unpubl. obs.). To date, only one study has successfully tracked the species throughout the winter over a single season, demonstrating the usefulness and relevance of the method (Bost et al. 2009). 
Tracking technique. To track animals during the complete winter inter-breeding period, we used lightbased geolocation techniques (Wilson et al. 1992, Hill 1994) deploying BAS MK4 miniaturised geolocators (global location sensing loggers, GLS, British Antarctic Survey), following Bost et al. (2009). These devices measure dim light level every minute and record the maximum value at the end of every $10 \mathrm{~min}$ period, together with time, enabling geolocation to be determined. In addition, ambient sea temperature is recorded once during every $20 \mathrm{~min}$ period of continuous immersion with a resolution of $0.0625^{\circ} \mathrm{C}$ and an accuracy of $\pm 0.5^{\circ} \mathrm{C}$. At both study colonies, we equipped moulting birds with GLS using specially designed leg bands (see Bost et al. 2009). On the east coast of Kerguelen ('Cap Cotter' colony), we selected 21 birds in April 2006 (11 male and 10 female; identified using bill morphometrics given by Williams \& Croxall 1991), and 16 birds in April 2007 (8 male and 8 female), without targeting the same nests between years. On Crozet at the 'Jardin Japonais' colony (north coast of Possession Island), we selected a total of 18 birds in April 2007 (9 male and 9 female). We did not retain reference tags on the colonies (for ground-truthing) over winter in order to maximise the number of equipped birds. Following Cherel et al. (2007), animals were blood-sampled on their recapture with the aim of measuring their foraging area and trophic level during the previous months using stable isotopic ratios of carbon $\left(\delta^{13} \mathrm{C}\right)$ and nitrogen $\left(\delta^{15} \mathrm{~N}\right)$, respectively. Control birds (i.e. not carrying a GLS device) were also sampled when they returned to land ( $\mathrm{n}=6,20$ and 10 for Kerguelen 2006, 2007 and Crozet 2007, respectively). Tracked birds were weighed before the winter trip (except for animals from Kerguelen in 2006) and on their return, to evaluate their mass gain. Control birds were also weighed at their return on Crozet $(n=20,10$ males and 10 females) to test for a possible effect of the device on the foraging success of the equipped birds.

Analysis of the tracks: description and comparison. Geolocation data were analysed following Thiebot \& Pinaud (2010), assuming a mean travel speed of $2 \mathrm{~km} \mathrm{~h}^{-1}$ in order to estimate the most probable track, using the package 'tripEstimation' in R 2.9.0 (R Development Core Team 2009, http://cran.r-project.org/web/ packages/tripEstimation/index.html). Two fixes per day (1 every $12 \mathrm{~h}$ ) were produced along the tracks, with a mean spatial accuracy of $180 \mathrm{~km}$ calculated on albatrosses (Phillips et al. 2004) that may be better for the slower penguins $(114 \mathrm{~km}$, estimated by Thiebot \& Pinaud 2010). Tracks were described and compared using a set of common parameters, based on the start and end dates of the trip; these dates were derived from the time of the first and last temperature records from each logger. Knowing the duration of the trip allowed us to cal- culate the time spent at sea, the minimum distance travelled, the maximum distance reached from the colony (hereafter called 'maximum range') and the proportion of time spent in each water mass calculated from the individual location estimates. Values are expressed as the mean \pm SD. Parametric ( $t$-test) and non-parametric (Wilcoxon and Kruskal-Wallis rank sum tests) statistical tests were used to detect significant differences among years, localities, sexes and time spent in each water mass; the statistical threshold was set at $p=0.05$. The spatial overlap of the winter home ranges for the 2 colonies was evaluated from the $95 \%$ kernel density contours (Wood et al. 2000). Kernels were relevant to capture the utilisation distribution of the birds, since similar tracking duration between individuals and identical frequency of locations produced by the geolocation technique provide similar numbers of locations per individual: consequently, no individual was overrepresented on the common grid used for the density contours. The package 'adehabitat' (http://cran.rproject.org/web/packages/adehabitat/index.html) was used for the kernel calculations, with a constant smoothing parameter (search radius) $h=2^{\circ}$, as recommended for these data (BirdLife International 2004). We used the function 'kerneloverlap' in this package, with the method 'Utilization Distribution Overlap Index' (UDOI), as recommended by Fieberg \& Kochanny (2005). A maximum theoretical overlap was calculated in each case between both home ranges to serve as a yardstick to evaluate how much the observed distribution differed from it. This was made by simulating an opposite bearing for the trips from one colony, Kerguelen 2007. In this simulated situation, longitude only was modified in order to conserve the thermal preference of the birds (i.e. latitude); we then calculated the respective overlap between this simulated distribution and the 2 other tracking datasets, from birds instrumented at Kerguelen in 2006 and at Crozet in 2007.

Identification of the wintering period. To characterise the wintering foraging areas, commuting/ migration periods had to be distinguished along the tracks. To achieve this, we first had to determine what we considered to be the wintering period. This was a trade-off between having a sufficiently large period enabling us to describe a significant habitat use by the birds, but which was not too large to result in temporal smoothing and homogenisation of the habitat parameters. We therefore used a 1 mo window according to the spatial likelihood of the locations obtained by the geolocation technique (Wilson et al. 1992, Hill 1994, Thiebot \& Pinaud 2010), and the level of environmental change usually found between seasons (Clarke 1988). To determine which month to consider, we relied on changes in mean swimming speed. Since periods of intense foraging behaviour can be detected via 
a decreased mean speed of the animal along its track and an increased time spent per sector, or increased sinuosity (Weavers 1992, Wilson 1995), we used the monthly mean speed of the birds we tracked to distinguish the migration phases from the wintering foraging areas (see Bost et al. 2009). One-way analysis of variance (ANOVA) was used to determine if there were significant differences (with $\mathrm{p} \leq 0.05$ ) in the monthly speeds. Due to the inherent inaccuracies associated with the geolocation technique, sinuosity could not be investigated in this study.

Habitat use during winter. We used the concept of the ecological niche defined as a hyper-volume delineated by environmental variables (Hutchinson 1957). To quantify marine habitat utilisation specifically during winter, we extracted the values of mapped variables from the 95, 75 and 50\% kernel density contours. These variables used were bathymetry (BATHY) and its gradient (BATHYG), sea surface temperature (SST) and its gradient (SSTG), SST anomalies (SSTA), sea surface chlorophyll a ( $\mathrm{chl}$ a) concentration (CHLA), mixed-layer depth (MLD) and eddy kinetic energy (EKE). MLD was a mean of the annual data obtained since 1941. The temporal resolution selected for dynamic variables was $1 \mathrm{mo}$, and the spatial grid was $1^{\circ}$ in accordance with the geolocation technique accuracy. These spatial data were obtained from the NOAA's ETOPO (www.ngdc.noaa.gov/mgg/gdas/gd_ designagrid.html?dbase=GRDET2), the Bloomwatch 180 (http://coastwatch.pfel.noaa.gov/coastwatch/CW BrowserWW180.jsp), the LOCEAN (www.loceanipsl.upmc.fr/ cdblod/mld.html) and the AVISO (http:// las.aviso.oceanobs.com/las/servlets/dataset) websites. Differences between variable utilisation among years and colonies were investigated in the available environment. This available environment was defined as the rectangle containing the maximum foraging distance from the colony in both longitudinal directions, and the maximum latitudinal extension of the observed distribution. The temperature differences from the GLS devices were compared over monthly timescales using Tukey's honestly significant difference multiple comparison of means test, with a $95 \%$ familywise confidence level.

\section{RESULTS}

GLS devices were recovered when macaroni penguins returned to their colonies at the beginning of the next breeding season. Minimal recovery rates of the equipped birds were $67 \%(14 / 21)$ and $63 \%(10 / 16)$ on Kerguelen in 2006 and 2007, respectively, and 67\% (12/18) on Crozet. These recoveries depend upon the opportunities to visit the colonies, which were less fre- quent at Kerguelen in 2007. Recapture rates were not significantly different between sexes for all animals studied ( $W=415, \mathrm{p}=0.462)$. Data were successfully extracted from 12 devices from Kerguelen in 2006 ( 7 from males, 5 from females) and 7 in 2007 (3 from males, 4 from females), and from 11 devices from Crozet (4 from males, 7 from females). While no sexual differences in their winter distribution was obvious, the low numbers of males and females precluded statistical investigation of potential sexual differences in the inter-breeding behaviour of birds in relation to years and localities.

\section{Overview of the whole tracks}

The at-sea distribution of all tracked macaroni penguins is shown in Fig. 1, using kernel density contours. This indicates large-scale movements of the birds over deep oceanic waters with no return to land during the inter-breeding period. Individual tracks showed that birds went neither to warmer waters north of the SSTF nor to colder waters south of the SACC.

Importantly, macaroni penguins from Kerguelen and Crozet were completely segregated whilst at sea during the inter-breeding period. Individuals from Kerguelen in 2006 and 2007 dispersed eastwards, mostly between 45 and $55^{\circ} \mathrm{S}$ with a limited latitudinal range. This eastward movement appeared relatively coherent both at the individual level within the same year, and at the population level between 2 successive years (2006 and 2007). Tracks were generally linear, suggesting a commuting strategy. Conversely, individuals from Crozet generally headed south-westwards, although one dispersed southwards and another almost eastwards. They consequently exhibited a greater latitudinal range than Kerguelen birds.

\section{Timing and statistics of the migrations}

There was no significant difference in the timing of departure between years for individuals from Kerguelen (mode on 19 April in both years; $W=28.5, \mathrm{p}=$ 0.141 , Table 1). Conversely, the timing of departure peaked on 30 April 2007 at Crozet, a date significantly later than at Kerguelen in the same year $(W=85, \mathrm{p}=$ 0.001 , Table 1,). Within each population, the timing of departure was similar between sexes. Dates of return were also similar between the 2 years at Kerguelen (24 and 22 October 2006 and 2007, respectively; $W=$ $56, \mathrm{p}=0.560$ ), while it was significantly later at Crozet (31 October, $t=3.45, \mathrm{p}=0.004$ ). Within each colony, males tended to return before females, but this had no significant effect on their overall mean trip duration 


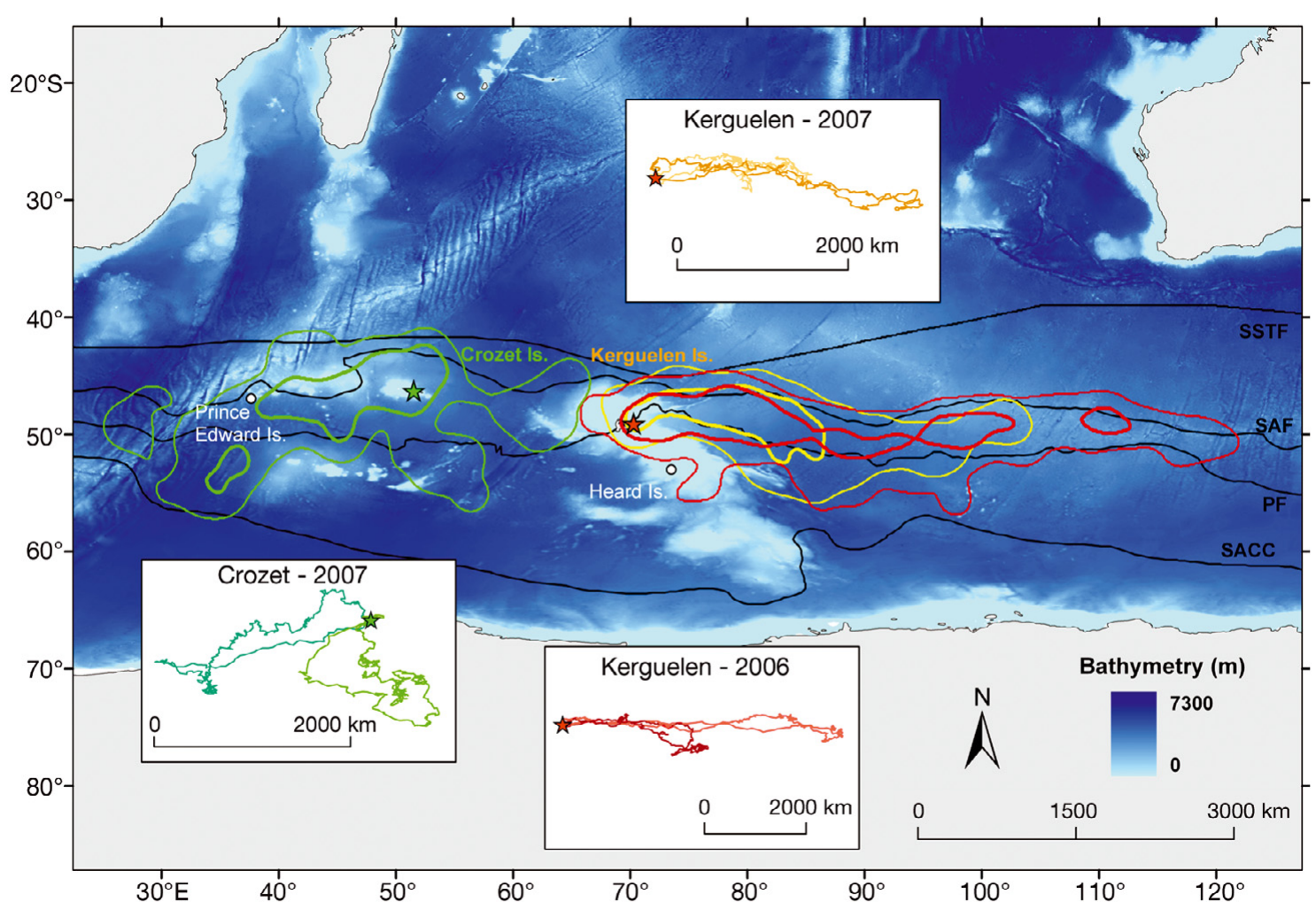

Fig. 1. Eudyptes chrysolophus. At-sea distribution of macaroni penguins during the winter inter-breeding period for birds from 2 colonies, 1 at Kerguelen (2006: red; 2007: yellow) and 1 at Crozet (green) in the southern Indian Ocean. Stars indicate location of colonies. Depth contours are displayed in the background. The $95 \%$ (thin lines) and $50 \%$ (bold lines) kernel density contours are also displayed. Within the inset boxes (one for each study site and year), 2 representative interpolated tracks are shown. Black lines represent the mean positions of the oceanographic fronts, from north to south: southern boundary of the Subtropical Front (SSTF), Subantarctic Front (SAF), Polar Front (PF), and southern boundary of the Antarctic Circumpolar Current (SACC)

$(t=0.82, \mathrm{p}=0.422)$ which lasted $\sim 6$ mo $(186 \pm 10 \mathrm{~d})$. The time spent at sea was similar between years at Kerguelen $(t=0.43, \mathrm{p}=0.670)$ and between the 2 localities $(t=-0.88, \mathrm{p}=0.399)$.

The total distance travelled during the whole winter averaged $9671 \pm 1280 \mathrm{~km}$. It was similar between years $(W=58, \mathrm{p}=0.196)$ and localities $(W=18, \mathrm{p}=0.069)$, and was almost identical between sexes within each colony. The maximal foraging range averaged $1778 \pm$ $902 \mathrm{~km}$ from the colony. At Kerguelen, it was significantly greater in 2006 than in $2007(t=2.38, \mathrm{p}=0.029)$, but it was similar between Kerguelen and Crozet in 2007 ( $t=-1.74, \mathrm{p}=0.106)$. No major difference in maximal foraging ranges was found between sexes.

Table 1. Eudyptes chrysolophus. Winter migration parameters for tracked birds from Kerguelen (2006 and 2007$)$ and Crozet (2007). In the Gender column, the number of individuals is given in brackets. Values are mean \pm SD

\begin{tabular}{|lcccccc|}
\hline $\begin{array}{l}\text { Locality and } \\
\text { year }\end{array}$ & Gender & $\begin{array}{c}\text { Departure date } \\
(\mathrm{dd} / \mathrm{mm})\end{array}$ & $\begin{array}{c}\text { Return date } \\
(\mathrm{dd} / \mathrm{mm})\end{array}$ & Days at sea & $\begin{array}{c}\text { Min. distance } \\
\text { travelled (km) }\end{array}$ & $\begin{array}{c}\text { Max. range from } \\
\text { colony }(\mathrm{km})\end{array}$ \\
\hline Kerguelen 2006 & All (12) & $19 / 04 \pm 14$ & $24 / 10 \pm 6$ & $189 \pm 15$ & $10431 \pm 1278$ & $2417 \pm 1008$ \\
& Males (7) & $20 / 04 \pm 16$ & $19 / 10 \pm 6$ & $185 \pm 16$ & $10229 \pm 1060$ & $2331 \pm 1019$ \\
Kerguelen 2007 & Females (5) & $19 / 04 \pm 13$ & $30 / 10 \pm 3$ & $194 \pm 13$ & $10714 \pm 1622$ & $2536 \pm 1099$ \\
& All (7) & $19 / 04 \pm 5$ & $22 / 10 \pm 5$ & $187 \pm 9$ & $9782 \pm 1111$ & $1597 \pm 485$ \\
& Males (3) & $15 / 04 \pm 4$ & $21 / 10 \pm 3$ & $185 \pm 9$ & $9194 \pm 457$ & $1871 \pm 611$ \\
Crozet 2007 & Females (4) & $21 / 04 \pm 5$ & $23 / 10 \pm 6$ & $189 \pm 7$ & $10223 \pm 1312$ & $1392 \pm 302$ \\
& All (11) & $30 / 04 \pm 1$ & $31 / 10 \pm 5$ & $184 \pm 5$ & $8772 \pm 789$ & $1196 \pm 462$ \\
& Males (4) & $30 / 04 \pm 2$ & $28 / 10 \pm 8$ & $181 \pm 7$ & $8930 \pm 1205$ & $1241 \pm 328$ \\
& Females (7) & $30 / 04 \pm 1$ & $01 / 11 \pm 2$ & $185 \pm 3$ & $8682 \pm 536$ & $1170 \pm 547$ \\
\hline
\end{tabular}


Regarding the proportion of time spent in each oceanic water mass, it is noteworthy that no bird went into the STZ (Fig. 2). There were substantial differences in the time spent in each of the 3 water masses for birds from Kerguelen in 2006 (Kruskal-Wallis $\chi^{2}=$ 28.2, p < 0.0001) and 2007 (Kruskal-Wallis $\chi^{2}=16.4$, $\mathrm{p}=0.0003$ ), and from Crozet in 2007 (Kruskal-Wallis $\left.\chi^{2}=13.9, p=0.001\right)$. On average, birds spent the bulk of their migration time (60 to $70 \%$ ) within the PFZ. The proportion of time spent within each water mass was consistent among years (Wilcoxon tests, p > 0.38 for each water mass) and was also similar between colonies (Wilcoxon tests, $\mathrm{p}>0.12$ for each water mass).

The UDOI was calculated between the 95\% kernel density contours of paired localities. Spatial overlap was very high (0.82) between the 2 successive years of study for Kerguelen, but no overlap was found with Crozet (UDOI $=0$ ). Overlap of the longitudinally reversed distribution of Kerguelen 2007 data was very weak (0.01) with observed data of 2006, while it amounted to 0.22 with observed data from Crozet.

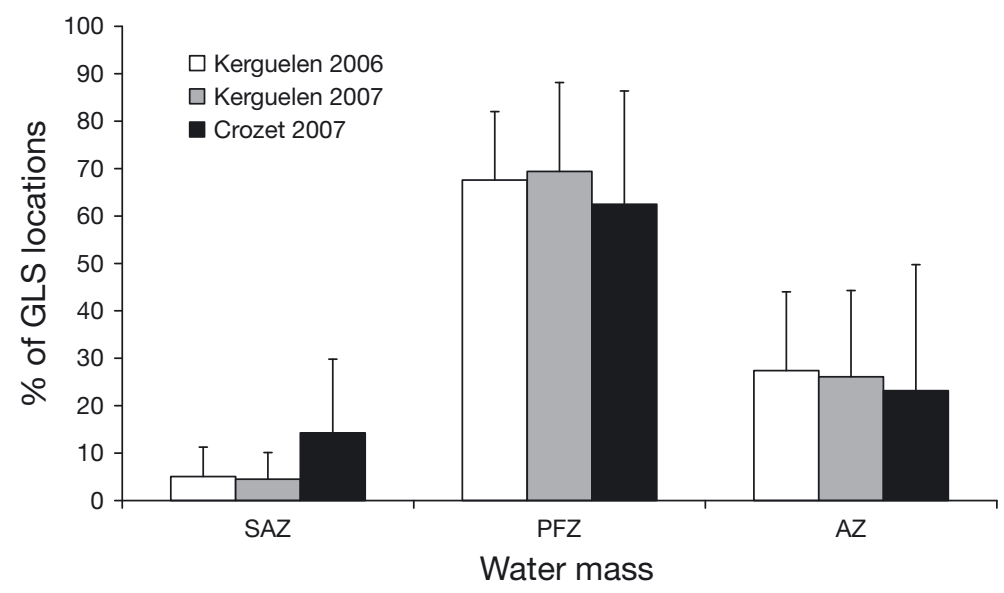

Fig. 2. Eudyptes chrysolophus. Proportions of locations in the different water masses for tracked birds from Kerguelen (2006 and 2007) and Crozet (2007). SAZ, PFZ and AZ indicate the Subantarctic, Polar Frontal and Antarctic zones, respectively. Values are mean + SD. Absolute number of locations was 4712, 2606 and 4083 for Kerguelen 2006, Kerguelen 2007 and Crozet 2007, respectively. GLS: geolocator

\section{Habitat use during the winter period}

In each colony there were substantial differences in the monthly travel speeds along the track (ANOVAs, Kerguelen 2006: $F_{7}=4.65, \mathrm{p}=$ 0.0002; Kerguelen 2007: $F_{7}=2.07, p=0.007$; Crozet 2007: $\left.F_{7}=4.71, \mathrm{p}=0.0003\right)$. Mean individual travelling speeds were 50.9 (42.8-69.0) $\mathrm{km} \mathrm{d}^{-1}$. Fig. 3 shows that penguins generally travelled faster when they were leaving and returning to their colonies, and conversely, they were slower in August and July for Kerguelen 2006, and in June and July for Kerguelen 2007 and Crozet 2007. For comparative purposes, we therefore focused on July to characterise the winter habitat of macaroni penguins in the southern Indian Ocean.

Available habitats of the macaroni penguins were similar between the 3 contexts (Table 2). However, large SD in the utilised

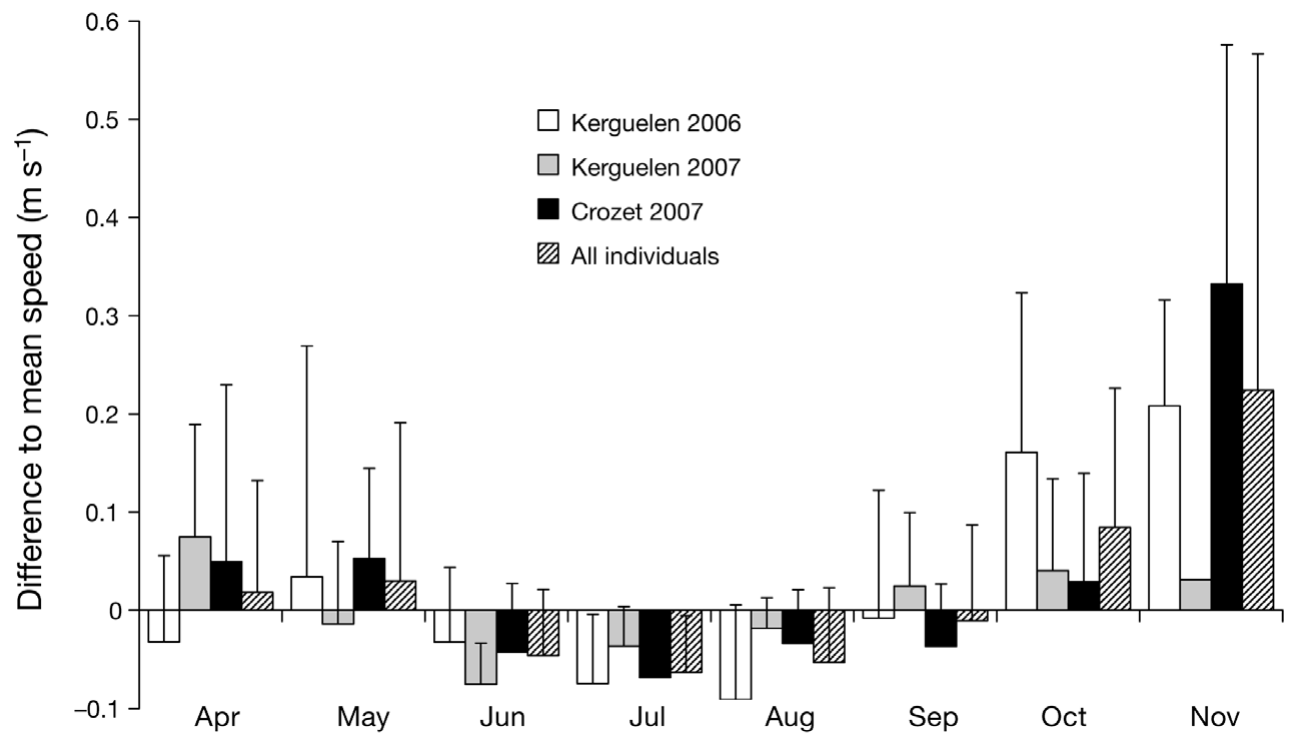

Fig. 3. Eudyptes chrysolophus. Mean monthly deviation from mean trip speed of the tracked individuals from Kerguelen (2006 and 2007) and Crozet (2007). Values are mean + SD 
parameters (Table 2) precluded drawing major conclusions about the penguins' respective habitat. All macaroni penguins from Kerguelen and Crozet used deep oceanic waters, mainly within the range 3000 to $4000 \mathrm{~m}$, with slightly deeper waters targeted in 2007 for the Kerguelen birds, and a much wider range of depths used by those from Crozet. Bathymetry gradients were highly variable in all cases. Thus, no clear differences emerged between years and colonies. SST in the $50 \%$ kernel density contour was $1^{\circ} \mathrm{C}$ lower in 2007 than in 2006, and similar between the 2 colonies. However, when considering temperatures directly recorded from the GLS devices (Fig. 4), values were approximately similar (in the range 3.0 to $3.5^{\circ} \mathrm{C}$ ) between years and colonies in the middle of winter, while they were different at both the beginning and end of the migrations. This suggests a high dependence of macaroni penguins with respect to the hydrothermal structure during winter. SST gradient was high in all cases, between 0.4 and 0.5 ; it was similar between years at Kerguelen, but was lower for Crozet birds. SSTA selected was highly variable; hence, no clear difference was found between years and colonies. CHLA targeted by the birds was low and consistent between years and colonies. On average, birds went into areas of high EKE, with very similar values between consecutive years at Kerguelen and a lower EKE at Crozet. MLD selected by birds was highly variable in all cases, and thus no clear differences emerged between years; however, inter-colony comparisons revealed very different means, with a shallower MLD for the Crozet wintering area.

\section{Isotopic signature}

Overall, the isotopic signatures of macaroni penguins were similar for control and tracked birds at the beginning of the breeding season (Wilcoxon and $t$-tests, $\mathrm{p}>0.54$ in each case). The only exception was the higher $\delta^{15} \mathrm{~N}$ value of control penguins at Kerguelen in $2006(t=-4.21, \mathrm{p}=0.0005)$. Consequently, the values of control and tracked birds were pooled to compare the isotopic signatures between years and colonies, except for the $\delta^{15} \mathrm{~N}$ value at Kerguelen in 2006. There were no significant differences in $\delta^{13} \mathrm{C}(t=$ 1.37, $\mathrm{p}=0.179)$ and $\delta^{15} \mathrm{~N}(t=0.569, \mathrm{p}=0.577)$ values between birds sampled at Kerguelen in 2006 and 2007, and there were also no significant differences in $\delta^{13} \mathrm{C}$ $(t=1.64, \mathrm{p}=0.113)$ and $\delta^{15} \mathrm{~N}(t=0.19, \mathrm{p}=0.853)$ values between birds sampled at Kerguelen and Crozet in 2007 (Table 3). No isotopic differences were found between males and females in any population (data not shown).

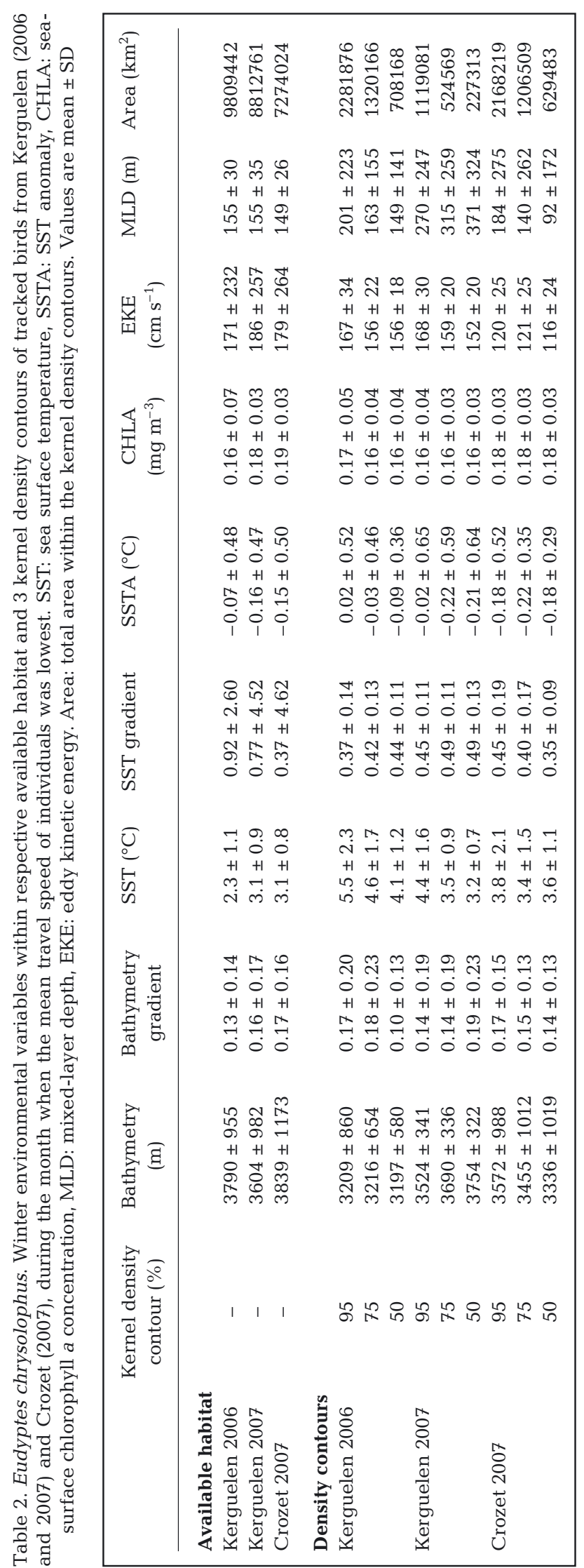




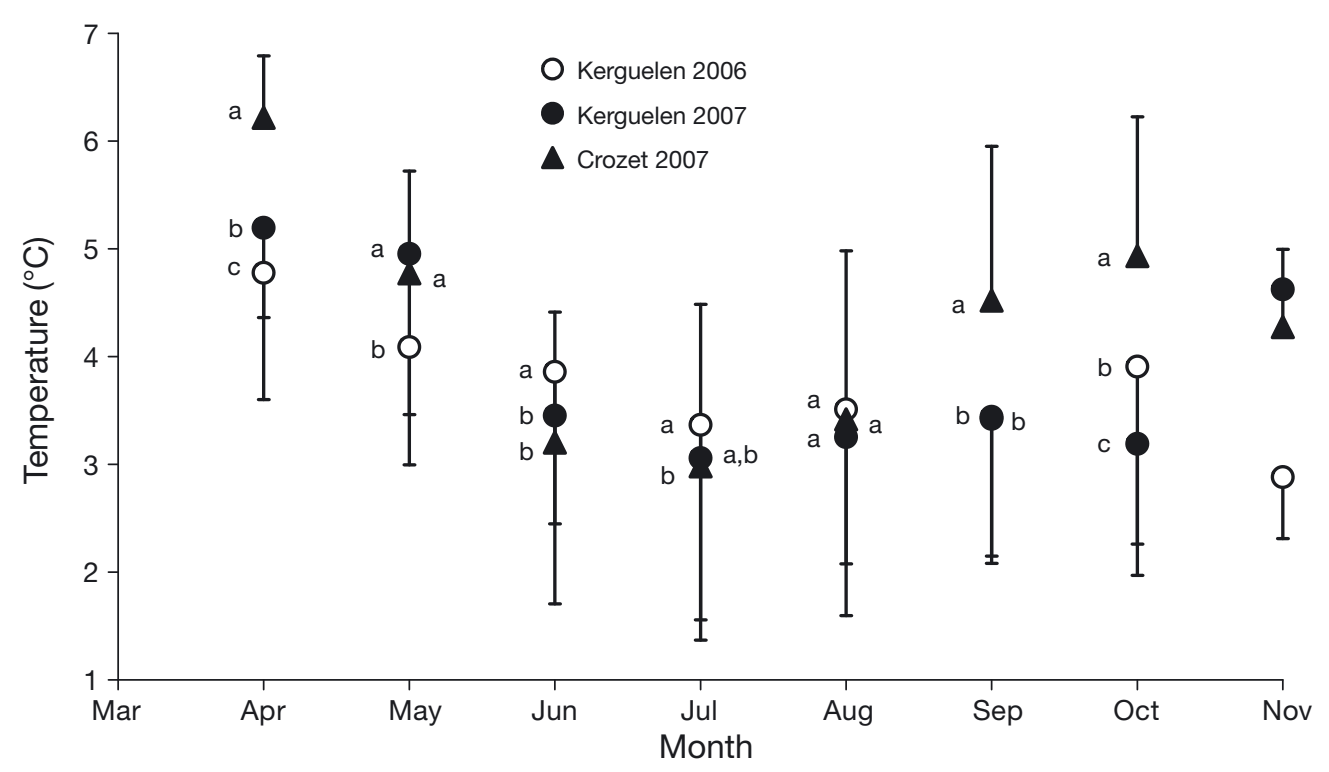

Fig. 4. Eudyptes chrysolophus. Monthly temperatures recorded by geolocator devices during the inter-breeding dispersal of macaroni penguins from Kerguelen in 2006 and 2007, and from Crozet in 2007. Symbols of the same shape indicate the same origin for the birds; the same colour indicates the same year. In each month, values not sharing the same superscript letter are significantly different. The low numbers of tracked individuals in November precluded any statistical comparisons. Values are mean \pm SD

\section{DISCUSSION}

The pioneering inter-annual and inter-colony comparisons carried out in this work support and generalise the previous finding that macaroni penguins undergo large-scale movements during winter (Bost et al. 2009). Our study highlights 2 new major findings. Firstly, macaroni penguins show strong inter-annual fidelity to their wintering site at the population level (Kerguelen in 2006 and 2007). Secondly, Kerguelen and Crozet birds were completely segregated at sea during the 2007 inter-breeding period. Tracked penguins did not radiate equally around their colonies; rather, they followed coherent, directional patterns of movement that were more typical of migration phenomena (Dingle \& Drake 2007). Our results (Figs. 1, 3 \& 4) suggest that macaroni penguins target predictable foraging areas in winter, thus concentrating their foraging effort within a restricted part of their potential range and suitable habitats (Wilson 1995, Bost et al.

Table 3. Eudyptes chrysolophus. Stable isotopic signature of whole blood from tracked birds on their spring return to the breeding colonies. Values are mean $\pm \mathrm{SD}$

\begin{tabular}{|lcccc|}
\hline Locality & $\mathrm{n}$ & Blood $\delta^{13} \mathrm{C}(\%)$ & Blood $\delta^{15} \mathrm{~N}(\%)$ & $\mathrm{C}: \mathrm{N}$ \\
\hline Kerguelen 2006 & 14 & $-21.4 \pm 0.3$ & $7.6 \pm 0.6$ & $3.5 \pm 0.2$ \\
Kerguelen 2007 & 7 & $-21.6 \pm 0.3$ & $7.4 \pm 0.3$ & $3.5 \pm 0.1$ \\
Crozet 2007 & 10 & $-21.6 \pm 0.7$ & $7.5 \pm 0.8$ & $3.4 \pm 0.2$ \\
\hline
\end{tabular}

1997). It is also worth noting that none of the tracked birds came ashore during the winter, thus remaining at sea for over $\sim 6$ mo, confirming previous studies based on land-based observations (Warham 1975) and winter diving data (Green et al. 2005).

\section{Methodological comments}

Our instrumentation of birds appears to have produced no adverse effects of device attachment, despite the very long trip duration, and in comparison with non-instrumented birds (Stahl et al. 1985). Legattached devices do not modify the diving performances of foot-propelled diving seabirds (RopertCoudert et al. 2009), also suggesting very low impact on flipper-propelled species. The percentage of instrumented macaroni penguins resighted after their winter trip was close to the return rates observed for a congeneric species (Raya Rey et al. 2007). We could not check the return rate of instrumented birds more than 3 times at the beginning of the breeding season due to logistic constraints. Further, resighting was compromised because the colour marking of birds with dye (see Bost et al. 2009) was partly erased after $\sim 6$ mo of immersion at sea, and legmounted devices could be hidden by the feathers. Consequently, as colonies are large and site fidelity is not complete in this 
species (Warham 1975), it is likely that some instrumented penguins were missed. Thus, the recapture rates were conservative and should be seen as minimum values.

Environmental differences between years and colonies are possibly less significant from an ecological point of view than from a statistical point of view, leading to the conclusion that macaroni penguins exhibit a strictly oceanic habitat use during winter. Fig. 4 strongly suggests that even though temperature conditions varied during departure and return, due to colony location or inter-annual variability, birds nevertheless targeted similar winter thermal conditions between years and between colonies. The GLS device temperature data suggest that macaroni penguins are thermal specialists, utilising predictable temperature ranges in winter.

Our study reveals only weak differences between the sexes in the horizontal movements of winter migrating penguins (cf. Ballard et al. 2010), thus suggesting a similar spatial niche for males and females. However, more subtle differences between sexes may appear when the vertical dimension of their niche is investigated (Green et al. 2005), indicating that sexual segregation may occur through a differential depth use by macaroni penguins.

\section{Inter-annual comparison}

All macaroni penguins tracked from Kerguelen went eastwards from the Kerguelen Plateau and exhibited a coherent migratory pattern both within and between years, suggesting site philopatry in this species in winter as well as in summer (Trathan et al. 2006). Winter site philopatry has already been shown for some flying seabirds (Phillips et al. 2005), but it was not known whether diving ones, which may potentially have a greater impact on marine resources (Woehler 1993, Brooke 2004), behaved in the same way. The highly coherent migration paths observed for the individuals from Kerguelen suggest a low impact of intra-specific competition on the exploitation of resources (Fretwell \& Lucas 1969). Consequently, the area located within the PFZ eastwards from Kerguelen is expected to host high levels of productivity and marine resources that are able to sustain hundreds of thousands to millions of macaroni penguins. Interestingly, the wintering area highlighted for these birds from Kerguelen (mostly spanning over 70 to $120^{\circ} \mathrm{E}$ and 45 to $55^{\circ} \mathrm{S}$ ) is encompassed within that of post-moult female elephant seals Mirounga leonina from the same locality, another major diving predator of the Southern Oceans (Bailleul et al. 2010). This strengthens the hypothesis that these are very profitable winter foraging areas for apex predators in this oceanic region.
There was a significant difference in the maximal range reached between the 2 study years, possibly due to individual differences in the sampled animals (as suggested by the difference in SD in both years, see Table 1). Nevertheless, the strong consistency in the post-breeding migration pattern obtained from Kerguelen birds suggests a long-term foraging strategy during the extended wintering period, which might be a general pattern in long-lived marine predators (Bradshaw et al. 2004, Phillips et al. 2005). According to Mueller \& Fagan (2008), a species' use of memory mechanisms that assume prior knowledge of a target location is explained both by life history traits and resource dynamics, which together shape populationlevel patterns. Resources with little spatial variability should facilitate sedentary ranges, whereas resources with predictable seasonal variation in spatial distributions should generate consistent migratory patterns, such as those obtained in this study. Consistent interbreeding migratory patterns exhibited by macaroni penguins from Kerguelen in 2 successive years therefore suggest the existence of a highly profitable, predictable but maybe non-permanent foraging ground available to apex predators in the area located within the PFZ eastwards from Kerguelen during winter.

\section{Inter-colony comparison}

Latitudinal predictability of the winter distribution of macaroni penguins was highlighted previously (see 'Methodological comments' above). However, even if tracked birds globally spent about two-thirds of their inter-breeding period within the PFZ, those from Crozet tended to be distributed more widely in latitude (Figs. 1 \& 2), as previously suggested by their isotopic signature (Cherel et al. 2007). Macaronis from Crozet probably benefited from the greater width of the PFZ in the Crozet region (Fig. 1), allowing them to diversify their trip heading when compared to animals from Kerguelen. Nevertheless, it must be remembered that oceanic fronts are dynamic structures, with seasonal as well as inter-annual movements, and their location during winter is less-well documented than during summer (Belkin \& Gordon 1996, Park et al. 2009).

Conversely, the longitudinal distribution of macaroni penguins during winter can be totally distinct at neighbouring breeding sites. Birds from Kerguelen and Crozet were completely segregated in their longitudinal range during the complete winter inter-breeding period, with individuals from Kerguelen heading eastwards and those from Crozet mostly departing in a south-westward direction. Interestingly, this absolute segregation was not the result of 2 distant home ranges, but rather appeared as a mutual exclusion 
leading to a tight juxtaposition (Fig. 1). However, this pattern was mainly due to a single individual from Crozet which foraged between the 2 archipelagos during winter. Consequently, the area between the 2 archipelagos was virtually free of tracked birds during the inter-breeding period. Why macaroni penguins did not forage there is difficult to interpret, but the most likely explanation may be because of unfavourable oceanographic conditions and consequent low abundance and/or availability of the main targeted marine resources in this area in winter, since animals from both colonies foraged at the same trophic level. Such spatial heterogeneity of prey in the southern Indian Ocean during winter is largely supported by the few studies that have been carried out outside the austral summer, which strengthened the link with contrasted local oceanographic regimes (e.g. Pakhomov \& Froneman 2000). However, the 2 Crozet birds that respectively exhibited a south-eastward and eastward trajectory came back to breed in time, and one of them showed a high body mass gain (data not shown). These results strongly suggest that marine secondary production during winter cannot be reliably inferred from surface chlorophyll concentrations, as chl a levels were low within the highlighted foraging areas (Table 2). On the other hand, we cannot exclude the presence of penguins from other colonies in the area between Crozet and Kerguelen (see below).

Finally, spatial segregation of marine populations and species (e.g. Grémillet et al. 2004, Cherel et al. 2007) is generally attributable to the evolution of niche shifts in order to reduce local competition that then increases an individual's probability of foraging success (Schoener 1986). Our study shows that 2 neighbouring populations of marine predators whose concomitant at-sea distributions are mutually exclusive (Fig. 1) can have the same trophic niche (Table 3). This strongly suggests parsimony in segregation mechanisms involved between parapatric organisms.

\section{Stable isotopes}

Taking into account the protein turnover rate in whole blood, the isotopic signature of macaroni penguins provided dietary information over the last 2 to 3 winter months at sea (Cherel et al. 2007). Geolocation analyses indicated that all tracked birds began their return migration $\leq 2$ mo before they arrived back at the colony. Most birds returned to the colony with an approximately linear trajectory and with high travelling speeds (Fig. 3). Hence, the blood isotopic signature integrates the feeding ecology over the last weeks on the wintering areas and along the return pathway. Overall, the 3 groups of tracked birds showed identical $\delta^{13} \mathrm{C}$ and $\delta^{15} \mathrm{~N}$ values, which were similar to those of macaroni penguins previously sampled in 2002 at Kerguelen and Crozet Islands (Cherel et al. 2007, 2008). Such consistency in the isotopic niche of consumers suggests little inter-annual variation in their trophic niche, which is in agreement with the consistent migratory behaviour of Kerguelen penguins that were tracked over 2 consecutive winters. Given this result, it is interesting that macaroni penguins from Kerguelen and Crozet had identical $\delta^{13} \mathrm{C}$ values (reflecting their foraging habitat), even though they wintered in different areas. The Southern Ocean is marked by a latitudinal, not a longitudinal, $\delta^{13} \mathrm{C}$ gradient at the base of the food chain that is reflected in consumers at higher trophic levels (Jaeger et al. 2010). Hence, the spatial accuracy of consumer $\delta^{13} \mathrm{C}$ values operates at the spatial scale of water masses (Cherel \& Hobson 2007). Indeed, the $\delta^{13} \mathrm{C}$ values of macaroni penguins are in agreement with both Kerguelen and Crozet birds foraging within the PFZ in winter.

GLS devices record valuable spatial information, but provide no indication of the feeding habits of the tracked birds. In spring, macaroni penguins arrive at the colony after a period of hyperphagia during which they build up large energy reserves in anticipation of their subsequent breeding fasts. The low blood $\delta^{15} \mathrm{~N}$ values at this time indicate that birds from Kerguelen and Crozet feed on low trophic-level prey during this critical period of their annual cycle (Cherel et al. 2007). It is likely that wintering macaroni penguins prey upon swarming crustaceans, including the euphausiids Euphausia vallentini and Thysanoessa spp. and the hyperiid amphipods Themisto gaudichaudii and Primno macropa. These pelagic crustaceans form the bulk of the food of the species in summer at both Kerguelen and Crozet (Ridoux 1994, Cherel et al. 2007, 2008). Since the macaroni penguin is a major seabird consumer (Brooke 2004), our study highlights the importance over winter of some sub-Antarctic crustaceans that have a trophic role similar to that of Antarctic krill E. superba farther south, in high-Antarctic waters (Bocher et al. 2001).

\section{CONCLUSION AND PERSPECTIVES}

We compared the inter-breeding distribution of 30 macaroni penguins from 2 successive years and 2 neighbouring breeding sites. We firstly revealed that macaroni penguins showed a strong inter-annual fidelity to their wintering site at the population level. Secondly, parapatric birds were completely segregated at sea during the same winter period. Finally, this study adds strength to the use of marine predators, such as seabirds, to investigate the distribution of pela- 
gic resources during winter. Our study also highlights that the PFZ is a major feeding habitat of marine top predators during the winter period.

One exciting question is to know where other populations of macaroni penguins are similarly distributed and to what extent they are segregated. Studies from neighbouring colonies on Crozet and Kerguelen archipelagos, as well as from neighbouring localities where numerous macaroni penguins also breed, such as at Heard and Prince Edward Islands (see Fig. 1), would reveal whether those birds mix with the birds reported here. In the same way, the winter food and feeding ecology of the huge population of macaroni penguins that breed in South Georgia (southern Atlantic Ocean) remain essentially unknown (but see Green et al. 2005), although these birds also seem to be distributed in the PFZ during winter (British Antarctic Survey unpubl. data). Such studies would allow us to refine our predictions about the spatial distribution of marine resources in winter within the Southern Ocean.

Macaroni penguins currently show a global decline, the causes of which are not well understood (Cresswell et al. 2008, Crawford et al. 2009, BirdLife International 2010). One important factor seems to be their body condition at the start of breeding, i.e. the level of body reserves accumulated during their winter inter-breeding trip (Crawford et al. 2006). The areas frequented during the inter-breeding period and the levels of secondary production encountered within these areas are probably key factors in this phenomenon. Therefore, in an era of rapid environmental change, studies of such areas are urgent. Hence, future studies should focus on marine productivity in the areas used by wintering predators to better understand the recent decline of macaroni penguins.

Acknowledgements. The Ethics Committee of the Institut Polaire Français Paul-Emile Victor (IPEV) approved the field procedure. We thank H. Maheo, M. Berlincourt, Q. Delorme, A. Knochel, R. Perdriat, J. Nezan, S. Mortreux and Y. Charbonnier for their help in the field, and C. Péron, A. Goarant, M. Louzao, C. Cotté and M. Authier for their help and advice on analyses. This work was supported financially and logistically by the ANR 07 Biodiv 'Glides', the IPEV (programmes no. 394, C. A. Bost, and 109, H. Weimerskirch), and the Terres Australes et Antarctiques Françaises.

\section{LITERATURE CITED}

Bailleul F, Authier M, Ducatez S, Roquet F, Charrassin JB, Cherel Y, Guinet C (2010) Looking at the unseen: combining animal bio-logging and stable isotopes to reveal a shift in the ecological niche of a deep diving predator. Ecography 33:709-719

Ballard G, Toniolo V, Ainley DG, Parkinson CL, Arrigo KR, Trathan PN (2010) Responding to climate change: Adélie penguins confront astronomical and ocean boundaries. Ecology 91:2056-2069
Behrenfeld MJ, Falkowski PG (1997) Photosynthetic rates derived from satellite-based chlorophyll concentration. Limnol Oceanogr 42:1-20

> Belkin IM, Gordon AL (1996) Southern Ocean fronts from the Greenwich meridian to Tasmania. J Geophys Res 101: 3675-3696 doi:10.1029/9SJC02750

BirdLife International (2004) Tracking ocean wanderers: the global distribution of albatrosses and petrels. BirdLife International, Cambridge

BirdLife International (2010) Species factsheet: Eudyptes chrysolophus. Available at www.birdlife.org/datazone/ speciesfactsheet.php?id=3857

Bocher P, Cherel Y, Labat JP, Mayzaud P, Razouls S, Jouventin P (2001) Amphipod-based food web: Themisto gaudichaudii caught in nets and by seabirds in Kerguelen waters, southern Indian Ocean. Mar Ecol Prog Ser 223: 261-276

Bost CA, Georges JY, Guinet C, Cherel Y and others (1997) Foraging habitat and food intake of satellite-tracked king penguins during the austral summer at Crozet Archipelago. Mar Ecol Prog Ser 150:21-33

Bost CA, Clerquin Y, Ropert-Coudert Y, Le Maho Y (2004) Exploitation of distant marginal ice zones by king penguins during winter. Mar Ecol Prog Ser 283:293-297

Bost CA, Thiebot JB, Pinaud D, Cherel Y, Trathan PN (2009) Where do penguins go during the inter-breeding period? Using geolocation to track the winter dispersion of the macaroni penguin. Biol Lett 5:473-476

> Bradshaw CJA, Hindell MA, Sumner MD, Michael KJ (2004) Loyalty pays: potential life history consequences of fidelity to marine foraging regions by southern elephant seals. Anim Behav 68:1349-1360

Brooke M de L (2004) The food consumption of the world's seabirds. Proc Biol Sci 271:S246-S248

Cherel Y, Hobson KA (2007) Geographical variation in carbon stable isotope signatures of marine predators: a tool to investigate their foraging areas in the Southern Ocean. Mar Ecol Prog Ser 329:281-287

> Cherel Y, Hobson KA, Guinet C, Vanpé C (2007) Stable isotopes document seasonal changes in trophic niches and winter foraging individual specialisation in diving predators from the Southern Ocean. J Anim Ecol 76:826-836

> Cherel Y, Ducatez S, Fontaine C, Richard P, Guinet C (2008) Stable isotopes reveal the trophic position and mesopelagic fish diet of female southern elephant seals breeding on the Kerguelen Islands. Mar Ecol Prog Ser 370: 239-247

> Clark CW, Mangel M (1984) Foraging and flocking strategies: information in an uncertain environment. Am Nat 123: 626-641

- Clarke A (1988) Seasonality in the Antarctic marine environment. Comp Biochem Physiol B 90:461-473

Crawford RJM, Dyer BM, Cooper J, Underhill LG (2006) Breeding numbers and success of Eudyptes penguins at Marion Island, and the influence of mass and time of arrival of adults. CCAMLR Sci 13:175-190

> Crawford RJM, Whittington PA, Upfold L, Ryan P, Petersen SL, Dyer BM, Cooper J (2009) Recent trends in numbers of four species of penguins at the Prince Edward Islands. Afr J Mar Sci 31:419-426

Cresswell KA, Wiedenmann J, Mangel M (2008) Can macaroni penguins keep up with climate- and fishing-induced changes in krill? Polar Biol 31:641-649

> Croxall JP, Prince ED (1980) Food, feeding ecology and ecological segregation of seabirds at South Georgia. Biol J Linn Soc 14:103-131

> Deagle BE, Gales NJ, Hindell MA (2008) Variability in foraging behaviour of chick-rearing macaroni penguins 
Eudyptes chrysolophus and its relation to diet. Mar Ecol Prog Ser 359:295-309

Dingle D, Drake VA (2007) What is migration? Bioscience 57: 113-121

Egevang C, Stenhouse IJ, Phillips RA, Petersen A, Fox JW, Silk JRD (2010) Tracking of Arctic terns Sterna paradisaea reveals longest animal migration. Proc Natl Acad Sci USA 107:2078-2081

Fieberg J, Kochanny CO (2005) Quantifying home-range overlap: the importance of the utilization distribution. J Wildl Manag 69:1346-1359

Fretwell SD, Lucas HJ Jr (1969) On territorial behaviour and other factors influencing habitat distribution in birds. Acta Biotheor 19:16-36

Furness RW, Camphuysen CJ (1997) Seabirds as monitors of the marine environment. J Mar Sci 54:726-737

Green JA, Boyd IL, Woakes AJ, Warren NL, Butler PJ (2005) Behavioural flexibility during year-round foraging in macaroni penguins. Mar Ecol Prog Ser 296:183-196

Grémillet D, Wilson RP, Wanless S, Chater T (2000) Blackbrowed albatrosses, international fisheries and the Patagonian Shelf. Mar Ecol Prog Ser 195:269-280

> Grémillet D, Dell'Omo G, Ryan PG, Peters G, Ropert-Coudert Y, Weeks SJ (2004) Offshore diplomacy, or how seabirds mitigate intra-specific competition: a case study based on GPS tracking of Cape gannets from neighbouring colonies. Mar Ecol Prog Ser 268:265-279

Grémillet D, Lewis S, Drapeau L, van Der Lingen CD and others (2008) Spatial match-mismatch in the Benguela upwelling zone: Should we expect chlorophyll and seasurface temperature to predict marine predator distributions? J Appl Ecol 45:610-621

Hardy AC (1936) Plankton ecology and the hypothesis of animal exclusion. Proc Linnean Soc Lond 148:64-70

Hill RD (1994) Theory of geolocation by light levels. In: Le Boeuf BJ, Laws RM (eds) Elephant seals: population ecology, behaviour and physiology. University of California Press, Berkeley, CA, p 227-236

Hutchinson GE (1957) Concluding remarks. Cold Spring Harbour Symp Quant Biol 22:417-427

Jaeger A, Lecomte V, Weimerskirch H, Richard P, Cherel Y (2010) Seabird satellite tracking validates the use of latitudinal isoscapes to depict predators' foraging areas in the Southern Ocean. Rapid Commun Mass Spectrom 24: 3456-3460

> Mueller T, Fagan WF (2008) Search and navigation in dynamic environments - from individual behaviors to population distributions. Oikos 117:654-664

Murphy RC (1936) Oceanic birds of South America. American Museum of National History, Macmillan, New York, NY

Pakhomov EA, Froneman PW (2000) Composition and spatial variability of macroplankton and micronekton within the Antarctic Polar Frontal Zone of the Indian Ocean during austral autumn 1997. Polar Biol 23:410-419

Park YH, Vivier F, Roquet F, Kestenare E (2009) Direct observations of the ACC transport across the Kerguelen Plateau. Geophys Res Lett 36:L18603 doi:10.1029/2009GL039617

Phillips RA, Silk JRD, Croxall JP, Afanasyev V, Briggs DR (2004) Accuracy of geolocation estimates for flying seabirds. Mar Ecol Prog Ser 266:265-272

Phillips RA, Silk JRD, Croxall JP, Afanasyev V, Bennett VJ (2005) Summer distribution and migration of nonbreeding albatrosses: individual consistencies and implications for conservation. Ecology 86:2386-2396
Pocklington R (1979) An oceanographic interpretation of seabird distributions in the Indian Ocean. Mar Biol 51:9-21

R Development Core Team (2009) R: a language and environment for statistical computing. R Foundation for statistical computing, Vienna

Raya Rey A, Trathan PN, Schiavini A (2007) Inter-annual variation in provisioning behaviour of southern rockhopper penguins Eudyptes chrysocome chrysocome at Staten Island, Argentina. Ibis 149:826-835

Ridoux V (1994) The diets and dietary segregation of seabirds at the subantarctic Crozet Islands. Mar Ornithol 22:1-192

Ropert-Coudert Y, Wilson RP (2005) Trends and perspectives in animal-attached remote sensing. Front Ecol Environ 3: $437-444$

Ropert-Coudert Y, Kato A, Poulin N, Grémillet D (2009) Legattached data loggers do not modify the diving performances of a foot-propelled seabird. J Zool (Lond) 279: 294-297

Schoener TW (1986) Resource partitioning. In: Kikkawa J, Anderson DJ (eds) Community ecology pattern and process. Blackwell, Carlton, p 91-126

Stahl JC, Derenne P, Jouventin P, Mougin JL, Teulières L, Weimerskirch H (1985) Le cycle reproducteur des gorfous de l'archipel Crozet: Eudyptes chrysolophus, le gorfou macaroni et Eudyptes chrysocome, le gorfou sauteur. Oiseau Rev Fr Ornithol 55:27-43

> Thiebot JB, Pinaud D (2010) Quantitative method to estimate species habitat use from light-based geolocation data. Endang Species Res 10:341-353

Timmermans KR, van der Woerd HJ, Wernand MR, Sliting M, Uitz J, de Baar HJW (2008) In situ and remote-sensed chlorophyll fluorescence as indicator of the physiological state of phytoplankton near the Isles Kerguelen (Southern Ocean). Polar Biol 31:617-628

Trathan PN, Green C, Tanton J, Peat H, Poncet J, Morton A (2006) Foraging dynamics of macaroni penguins Eudyptes chrysolophus at South Georgia during brood-guard. Mar Ecol Prog Ser 323:239-251

Ward P, Zahavi A (1973) The importance of certain assemblages of birds as 'information-centres' for food-finding. Ibis 115:517-534

Warham J (1975) The crested penguins. In: Stonehouse B (ed) The biology of penguins. Macmillan, London, p 189-269

Weavers BW (1992) Seasonal foraging ranges and travels at sea of little penguins Eudyptula minor, determined by radiotracking. Emu 91:302-317

Williams TD, Croxall JP (1991) Annual variation in breeding biology of macaroni penguins, Eudyptes chrysolophus, at Bird Island, South Georgia. J Zool (Lond) 223:189-202

Wilson RP (1995) Foraging ecology. In: Perrins CM, Bock WJ, Kikkawa J (eds) The penguins. Oxford University Press, Oxford, p 81-106

Wilson RP, Ducamp JJ, Rees G, Culik BM, Niekamp K (1992) Estimation of location: global coverage using light intensity. In: Priede IM, Swift SM (eds) Wildlife telemetry: remote monitoring and tracking of animals. Ellis Howard, Chichester, p 131-134

Woehler EJ (1993) The distribution and abundance of Antarctic and sub-Antarctic penguins. Scientific Committee on Antarctic Research, Cambridge

> Wood AG, Naef-Daenzer B, Prince PA, Croxall JP (2000) Quantifying habitat use in satellite-tracked pelagic seabirds: application of kernel estimation to albatross locations. J Avian Biol 31:278-286

Editorial responsibility: Rory Wilson,

Swansea, UK
Submitted: July 14, 2010; Accepted: September 25, 2010

Proofs received from author(s): December 15, 2010 